\title{
Librarians' Perspectives on the Factors Influencing Research Data Management Programs
}

\author{
Ixchel M. Faniel and Lynn Silipigni Connaway
}

\begin{abstract}
This qualitative research study examines librarians' research data management (RDM) experiences, specifically the factors that influence their ability to support researchers' needs. Findings from interviews with 36 academic library professionals in the United States identify 5 factors of influence: 1) technical resources; 2) human resources; 3) researchers' perceptions about the library; 4) leadership support; and 5) communication, coordination, and collaboration. Findings show different aspects of these factors facilitate or constrain RDM activity. The implications of these factors on librarians' continued work in RDM are considered.
\end{abstract}

\section{Introduction}

Many contend librarians are well suited to support RDM needs on their campuses. Luce urges librarians to take advantage of their core strengths to provide outreach and engagement early in the research lifecycle, establish common ground among key stakeholder groups, and lead the development of metadata standards. ${ }^{1}$ Gabridge describes how librarians can act as intermediaries between researchers and data repositories. ${ }^{2}$ Walters and Skinner outline roles for librarians that would strengthen the infrastructure, content, and services required for digital curation and preservation. ${ }^{3}$

RDM "consists of a number of different activities and processes associated with the data lifecycle, involving the design and creation of data, storage, security, preservation, retrieval, sharing, and reuse, all taking into account technical capabilities, ethical considerations, legal issues, and governance frameworks." ${ }^{4}$ It describes not only the services libraries offer, but also key components of the social and technical infrastructures that are needed. Although the RDM literature recognizes the importance of the services and supporting infrastructures, aspects of the phenomenon that are highlighted depend on each study's focus.

Research into RDM still is in the early stages, and few studies focus on the library community's RDM experiences. Of those that do, most studies have been quantitative and outline RDM services and the competencies and training that librarians need to support researchers. ${ }^{5}$ Although the studies provide insight into RDM activities and allow for useful comparisons, they lack a richly detailed understanding about what the 
library community is experiencing. One exception is Pinfield et al. ${ }^{6}$ Based on interviews with 26 library professionals from different institutions in the United Kingdom, the authors model an institutional approach to RDM.

Like Pinfield et al., this study also is qualitative; but, rather than present a model, it considers librarians' RDM experiences, particularly the factors that influence their RDM support. This study draws from Pinfield et al. ${ }^{8}$ and dictionary definitions of influence to define influencing factors as people or things that affect someone or something and act to facilitate or constrain the person or thing. ${ }^{9}$ This study poses the following research question: What factors influence librarians' ability to support researchers' RDM needs? The analysis of interview data from 36 academic library professionals in the United States identifies 5 factors of influence: 1) technical resources; 2) human resources; 3) researchers' perceptions of the library; 4) leadership support; and 5) communication, coordination, and collaboration. Findings are reported in detail after reviewing the RDM literature and discussing the research methodology. A discussion outlining the implications of the findings for librarians supporting RDM programs at their institutions follows.

\section{Literature Review}

The Pinfield et al. institutional RDM model is library focused and has four key RDM components: 1) drivers; 2) program elements; 3) influencing factors; and 4) stakeholders. According to the authors, the drivers (storage, security, preservation, compliance, quality, sharing, jurisdiction) provide the causal reasons why RDM programs are being pursued. The program elements (strategies, policies, guidelines, processes, technologies, services) are activities carried out to support RDM. Stakeholders within the institution (library, information technology (IT) services, academic departments, senior university managers, research support services, other support services) interact with the program elements based on their roles and relationships. Last, there is a two-way relationship between the influencing factors (acceptance, cultures, demand, incentives, roles, governance, politics, resources, projects, skills, communications, context) and program elements that acts to facilitate or constrain RDM activity. ${ }^{10}$

There are reports, methodologies, and case studies that address aspects of the Pinfield et al. ${ }^{11}$ model. For instance, a report describing how to start conversations among stakeholder groups to formulate a campuswide RDM policy ${ }^{12}$ addresses the who, what, and how of the model with respect to policy development. Data Curation Profiles and Data Asset Framework methodologies guide RDM service development based on an understanding of data holdings and current data curation and preservation policies and practices that is rooted in researchers' needs. ${ }^{13}$ Case studies of RDM implementations address various RDM drivers, program elements, stakeholders, and influencing factors. ${ }^{14}$

Other studies focus on one aspect of the model, such as librarians' current and planned RDM services. A key finding across these studies shows that data discovery and access services are more widely implemented than data management and curation services. ${ }^{15}$ In the United States and Canada, finding and citing data and other informational services, such as data management planning consultations and data web guides and finding aids, are being offered and planned more frequently than technical services that support managing, curating, and preserving data. ${ }^{16}$ Kotarksi et al. report more libraries in Europe offering services to support researchers' need to find data than their need to archive or create data management plans. ${ }^{17}$ Data discovery and data management planning services also are well represented among libraries in Australia, Ireland, New Zealand, and the United Kingdom, with data curation and other technical services on the horizon. ${ }^{18}$

Another series of studies examining RDM competencies and training provides some insight into the lag in technical service offerings. Proposing a set of 32 competencies librarians need to support RDM, Auckland reports that subject librarians perceive 9 skill 
gaps related to preserving research outputs: data management and curation, complying with various funders' mandates, data manipulation tools, data mining, metadata advice and use, preservation of project records, sources of research funding, metadata schema development, and discipline standards and practices. ${ }^{19}$ Studies in Australia, New Zealand, and Italy report the following as important knowledge areas for repository staff: open access and intellectual property and copyright, government reporting requirements, collection development and metadata, and repository software. ${ }^{20}$ Science librarians affiliated with the Association of Research Libraries (ARL) mention needing to develop knowledge of the data lifecycle and subject-specific knowledge as well as communication, networking, reference, metadata, and software and computer skills, to help researchers with data management. ${ }^{21}$ Library professionals in Australia, Ireland, New Zealand, and the United Kingdom also report needing disciplinary knowledge and knowledge of research methods and processes to support data management, but they report the need for data curation, technical, and information and communication technology (ICT) skills to a greater degree. ${ }^{22}$

Clearly, technical skills are critical. Xia and Wang provide further evidence showing the top preferred job qualifications for social science data librarians and professionals are technical (such as metadata standards, data resources, HTML \& XML, data management, data analysis). ${ }^{23}$ However, required job qualifications show nontechnical skills such as communication and project management appear as frequently as technical skills such as statistical packages and metadata standards. ${ }^{24}$ Cassella and Morando also found 42 to 55 percent of repository managers rated nontechnical skills such as teamwork, project management, and communication and advocacy as very important. ${ }^{25}$ In addition, soft skills, such as project management and leadership, are showing up in studies of training needs along with the technical skills, such as knowledge of interoperability standards and protocols, metadata, statistics, and repository software. ${ }^{26}$

When it comes to training, almost 55 percent of ARL science librarians have or are actively acquiring the skills needed to help scientists with data management, leaving 45 percent who are unprepared or unsure of their aptitude. ${ }^{27}$ European librarians fare slightly better, with 68 percent reporting that their libraries have or are investing in developing the right skills to support RDM. ${ }^{28}$ Looking across studies, few library staff are receiving formal training. ${ }^{29}$ Most learn on the job through self-study or in-house training. ${ }^{30}$ Of the library directors in the United States and Canada who provide training opportunities, most provide support for conferences and workshops, followed by courses, and in-house staff workshops and training, ${ }^{31}$ but librarians have definite preferences. In Europe, librarians believe the best way to develop needed skills is through continuing professional development courses, followed by integrating data management into professional training courses, and keeping pace with practical literature and guidelines. ${ }^{32}$ In Australia, New Zealand, Ireland, and the United Kingdom, librarians prefer external rather than internal continuing professional development opportunities. ${ }^{33}$

In sum, the Pinfield et al. study provides a comprehensive framework to consider when contemplating RDM programs. ${ }^{34}$ The RDM literature addresses aspects of the framework, such as the RDM services that librarians support and common skill gaps they must address to provide such support. Less clear are details about the factors that influence librarians' ability to support researchers' RDM needs; therefore, this study addresses these influencing factors based on interviews with academic librarians.

\section{Methodology}

In 2012 and 2013, qualitative data were collected from 36 academic library professionals in the United States via individual and focus group interviews. These data collection methods are useful in the early stages of researching new and evolving phenomena because they allow for in-depth discussion and rich detail. ${ }^{35}$ Individuals are able to 
express their ideas and experiences in their own words and stories. ${ }^{36}$ Both convenience and snowball sampling techniques were used to recruit study participants. All participants were provided informed consent documents that described the study and their rights as study participants and signed and submitted consent forms.

The individual semistructured interviews were conducted with 10 library professionals via telephone. The interviews lasted 60 minutes on average and were audiorecorded and transcribed. Library professionals participating in individual interviews were recruited based on contact with library administrators. Those who agreed to participate were asked for the names of other library professionals who might be interested in participating. The protocol for the individual interviews asked participants about current and planned RDM services, advantages, and challenges associated with helping researchers with RDM, what made it difficult and easy to spend time helping researchers, supporters versus detractors of RDM efforts, and perceived competence and confidence that they were helping researchers and meeting needs (see appendix A).

Twenty-six library professionals participated in one of three focus group interviews conducted at the 2013 Association of College and Research Libraries (ACRL) conference. Each interview lasted approximately 60 minutes and was audiorecorded and transcribed. The academic librarians who participated in the focus group interviews were ACRL conference attendees recruited via listservs such as the ACRL Digital Curation Interest Group and the ACRL Digital Humanities Interest Group. In addition, the ACRL conference registration list was used to recruit participants based on their job titles. The focus group interviews were semistructured, and the protocol was modeled after the individual interview protocol. Some changes were made given our experiences with the individual interviews and the change in data collection methods, but the topics of inquiry were similar (see appendix B). They included: current versus planned RDM services, institutional RDM champions, motivations behind RDM services, librarians' RDM involvement and the value they brought versus gained, challenges and benefits of helping researchers, suggestions and ideas that would make it easier for librarians to help researchers, and librarians' perceived confidence that they were helping researchers and meeting needs.

A team of two worked closely to perform thematic analysis. After reviewing all transcripts, the team worked together to develop a code book. The team identified and defined an initial set of codes based on the individual and focus group interview protocols and expanded the set as new codes emerged from ongoing analysis.

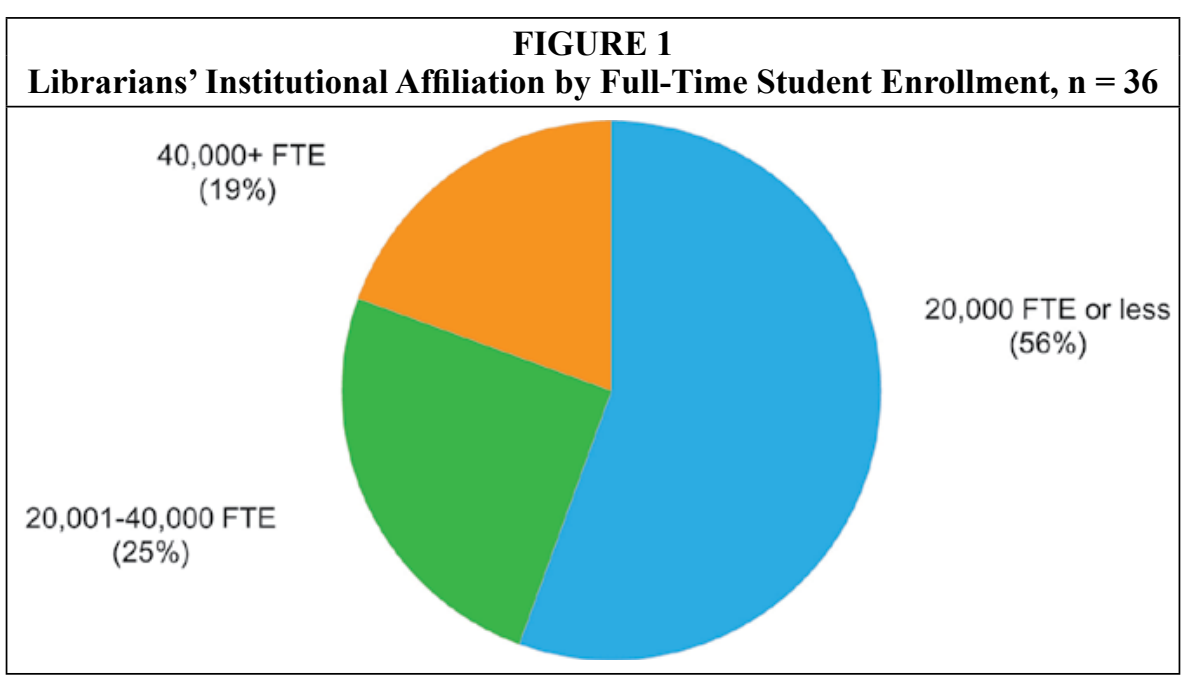


For example, transcripts were coded for mentions of data service offerings, service delivery methods, data service benefits and challenges, and opinions about what would make data service provision easier. Working together, the team coded the same transcript individually, calculated interrater reliability using Scott's Pi, and then met to discuss and resolve coding discrepancies. The team's interrater reliability was .75. A second cycle of thematic and numerical analysis was conducted to report the results that follow.
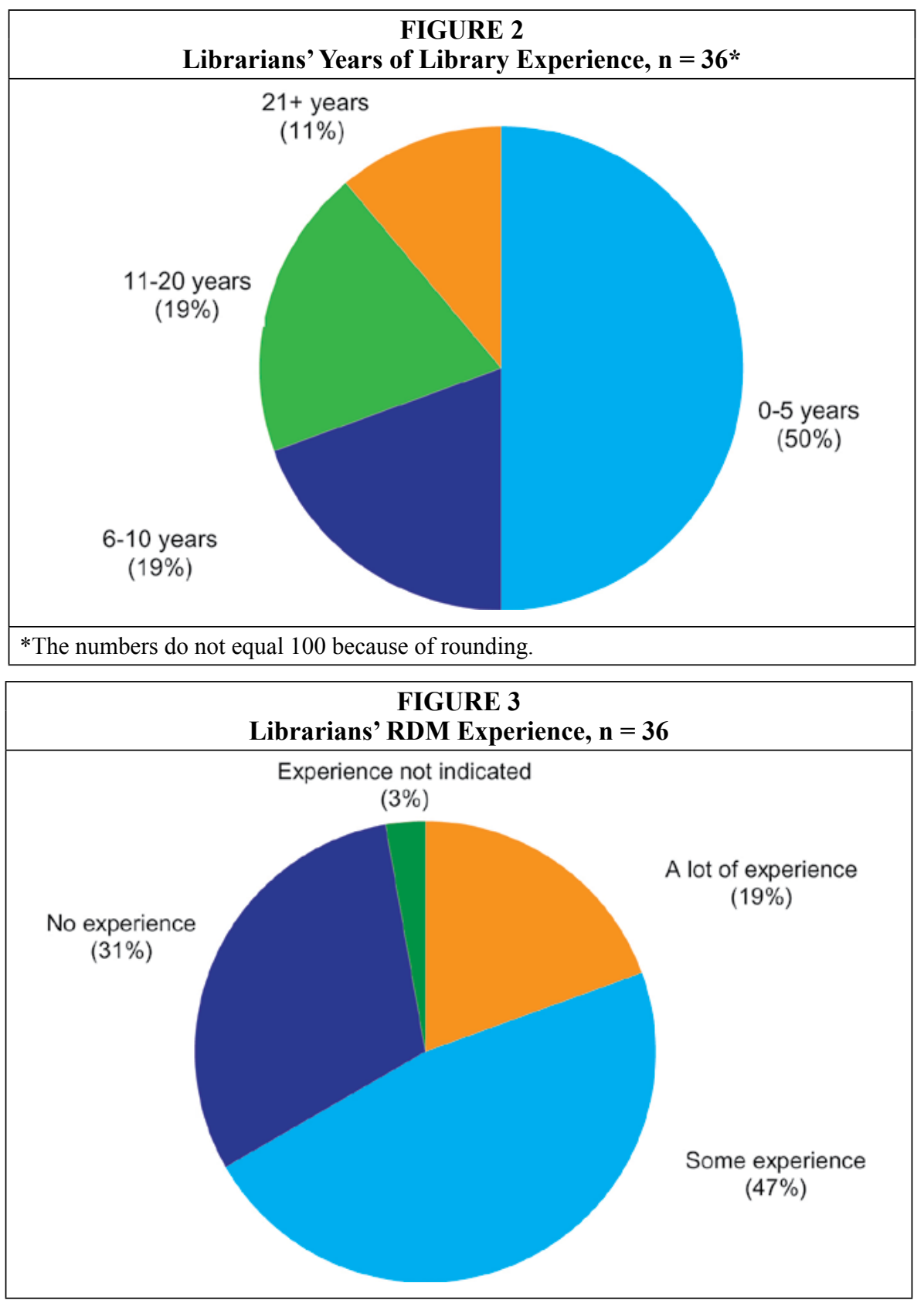


\section{Results}

Of the 36 librarians who participated in this study, 56 percent worked at institutions with a full-time student enrollment (FTE) of 20,000 or less, 25 percent at institutions with 20,001 to 40,000 FTE, and 19 percent with an FTE greater than 40,000 (see figure 1). Although demographic data were not submitted by all participants, there were enough data to provide some approximations. Most participants were female $(86 \%)$, and less than 45 years old (53\%). Almost 70 percent were early in their library career with 10 years of experience or less and 66 percent had some or a lot of RDM experience (see figure 2 and figure 3). The participants also represented a variety of roles within the library such as subject specialist, liaison librarian, scholarly communication librarian, reference librarian, data management specialist, digital initiatives librarian, and head of library systems.

\section{RDM Service}

A discussion of the service component of RDM programs, which librarians mentioned providing or planning to provide, puts the influencing factors in context. Providing or planning to provide researchers support when writing data management plans $(61 \%)$, depositing data $(67 \%)$, and managing data $(41 \%)$ were mentioned the most. Typically, these top three services were delivered to researchers via consultation, education, and outreach rather than collaboration.

On the verge of launching data services at her institution, Librarian 13 envisioned support for researchers writing data management plans as "subject librarians meeting with grad students and faculty, and going over the guidelines for grant funding for data management, and helping them kind of understand what kind of information they're going to need to provide, in order to have a good grant proposal." Librarians preferred this type of early engagement because it provided an opportunity to discuss funding agency guidelines and determine the feasibility of researchers' plans to manage data. Unfortunately, several librarians mentioned being contacted a day or two before grant proposals were due, which left no time to discuss or negotiate alternatives based on the researchers' needs and campus resources.

A wide range of activities centers on data deposit services, from reaching out to researchers to identify data for deposit, to helping them curate and document their data. The time commitments varied depending on the service levels required and the amount of work involved. Outreach to identify data for deposit ranged from presentations at faculty meetings to personalized e-mails and meetings. The liaising activities performed to ensure that researchers' needs were being met at disciplinary repositories took time as well. Librarian 04 explained her work acting as an intermediary:

"I'll often do a lot of work communicating with that repository to sort of help smooth the path for the faculty member ... I find it sort of valuable and meaningful for me to do a lot of work with the repository, helping to make sure that I know what they need, helping the faculty members sort of comply with that. And sometimes ... I've been sort of lobbying for services the faculty member needs."

Librarians envisioned data management services supporting researchers' day-to-day needs such as "file protection, file organization, documentation as you're collecting the data" (Librarian 22). Librarians preferred providing guidance, whether instruction or consultation, to early-career researchers and early in the research cycle. They were most successful with the former, working with graduate students primarily. Although data management services were mentioned the least, they were not the least important. Librarian 35 discussed her work with a researcher who needed help managing 30 years of data: 
"She's still using it [the data] for teaching and research ... It's getting worse and worse, and she cannot find it, and some of them are already not accessible, as it is on some ... tapes, some cassettes."

Without early and ongoing data management activities, Librarian 17 explained how "it [is] so much harder to go backwards, you know, and say 'Actually, if we had organized the files in this way we can put them in this place easier.'" The difficulty was due in part to both researchers and librarians needing to spend additional time cleaning and preparing data and documentation at the end of the research project and in part to time being in short supply.

\begin{tabular}{|l|c|}
\hline \multicolumn{2}{|c|}{ TABLE 1 } \\
\multicolumn{2}{|c|}{ Factors that Influence Librarians' RDM Support, } \\
\multicolumn{1}{|c|}{ Factors } & $\mathbf{3 6}$ \\
\hline Human resources & \% of Librarians \\
\hline Communication, coordination, collaboration & $78 \%$ \\
\hline Technical resources & $67 \%$ \\
\hline Leadership support & $53 \%$ \\
\hline Researchers' perceptions of the library & $31 \%$ \\
\hline
\end{tabular}

\section{Influencing Factors}

Findings indicated five factors that influenced librarians' ability to support researchers' RDM needs: 1) technical resources; 2) human resources; 3) researchers' perceptions about the library; 4) leadership support; and 5) communication, coordination, and collaboration (see table 1). In each of these instances, librarians described situations where different aspects of the factors acted to facilitate or constrain RDM support.

\begin{tabular}{|c|c|}
\hline \multicolumn{2}{|c|}{ TABLE 2 } \\
Technology Resources that Facilitate and Constrain Librarians' RDM \\
Support, $\mathbf{n = 3 6}$
\end{tabular}

\section{Technical Resources}

Technology solutions, particularly digital repositories, were mentioned as part of an envisioned RDM program that would make it easier for librarians to support researchers' needs, but these solutions raised associated data storage and preservation challenges (see table 2). Librarians 16, 14, and 17 discussed the financial commitment associated with sustaining repositories in the long term, which was expected to stretch most libraries' infrastructures beyond capacity given shrinking budgets and uncertain pricing structures:

"Are we going to look for researchers to write to their grants, data storage costs now? Because as a library, we can't afford to take on these costs ... our IT folks say, 'We 
can't store that in perpetuity' ... we're starting conversations [with the supercomputer center] but ... [t] hey don't want to commit to storing something for 100 years."

"Yeah, I think the other issue connected with that is the pricing structure. I mean, how do we charge if they're writing it into a grant? It's grant funding, it goes away, so how do you pay for preservation into perpetuity when you're getting a one-time payoff?"

"We can talk about best practices and we can talk about management and writing for your grant and so on but when it comes to actually putting that data somewhere, that you can get to again ... that is something that I really don't feel like there is a good answer for."

Long-term storage and preservation of various file formats across disciplines was a concern as well. Others questioned whether their current institutional repository (IR) was the best solution for data discovery and access given front-end functionality. "I mean we have an institutional repository, and you know, yes, you can store data in there now ... but do we have a platform that's useful, that people can retrieve stuff and do with it what they want?" (Librarian 34) In short, librarians saw an IR as a means to facilitate RDM, but there were several unanswered questions about data storage and preservation for long-term data discovery and access that acted as constraints.

\begin{tabular}{|l|c|}
\hline \multicolumn{2}{|c|}{ TABLE 3 } \\
Human Resources that Facilitate and Constrain Librarians \\
RDM Support, $\mathbf{n}=\mathbf{3 6}$
\end{tabular}

\section{Human Resources}

Full-time RDM experts and continuing education and training were mentioned as facilitating librarians' ability to support RDM needs, but librarians also faced challenges given the demands on their time and the limited number of experts on staff (see table 3). Several librarians mentioned hiring or planning to hire staff in key areas of expertise to help them support RDM, such as data management, electronic resources, e-research, scholarly communication, and technology. Others mentioned how their existing areas of expertise were being used to support RDM. One librarian drew on his experience as a lawyer to develop terms of service agreements. Another used his archival experiences in engineering and research and development organizations. Others drew on their subject expertise and prior research experience.

Yet even with experts on staff, librarians expressed concern about scaling RDM, because they did not have enough skilled staff. Thirty-one percent of the librarians mentioned time challenges. The difficulty meeting existing job responsibilities along with new RDM demands was mentioned most frequently. Librarian 05 attributed this difficulty to the common staffing model in academic libraries, which was spreading librarians thin enough to do a little bit of everything: 
"So already it's like instruction, outreach, reference, collections ... then add like open access and whatever, the various committees, and so to add like one other new area of expertise ... It's just one more thing to have to do and something to have to learn about again ... So it's just a lot to keep up on ..."

Librarian 01 explained it as the trouble with success:

“... it's just not scalable. So if we're successful, we're in big trouble, because we just don't have the time, it could be a real time sink. I think it would be really fun, but I wouldn't be able to do anything else I'm supposed to do."

Even in instances when job responsibilities could be reallocated, Librarian 16 explained that the time savings was not straightforward, because "you've got some amount of time devoted to the learning, before you can actually do the doing." As Librarian 22 noted, data management and curation were not traditional areas of strength for librarians

"Our strengths tend to be on the end of it in terms of putting things in and archiving them and maintaining them over a longer period and not that 'what are you doing with it while you're using it' sort of thing."

Several librarians talked about the initial learning curve they faced getting up to speed on the variety of data management and curation issues well enough to help researchers (such as copyright and intellectual property laws, federal funding guidelines and requirements, existing tools and disciplinary repositories, disciplinary knowledge, current research and associated data, data formats and documentation, and metadata standards). Moreover, librarians mentioned ongoing learning through continuing education and on-the-job training as something they wanted to pursue; both education and training were mentioned as facilitating RDM support. Continuing education typically occurred through conferences, webinars, classes, workshops, e-mail groups, self-study, and peer instruction, whereas on-the-job experiences were more varied. In one instance, librarians, archivists, and technologists were brought together to get hands-on experience working with each other on projects during several summers. In another, Librarian 13 discussed the planning underway for an immersive one- to twoyear hands-on experience pairing subject librarians with data experts to meet faculty and students about their research data needs:

" ... the plan is that, our social sciences librarians will team up with the [research center], for the first year or two, to get experience, to be in the room, to see exactly what kind of questions you need to ask and what kind of information you need to gather. And the science people will go with the e-research librarian with their meetings with faculty and students that do the same thing."

Although not facilitators, librarians expressed enthusiasm when asked about the benefits of providing RDM support. Despite the time and staffing challenges, they described the work as interesting, enjoyable, satisfying, and rewarding (see table 4). They were excited to hear about research and to help faculty and students with it. As Librarian 21 explained:

"It's really rewarding to be able to step in and offer even just a small bit of 'Try this metadata schema, this might work for you.' It's really rewarding. And it's just fun ..." 


\begin{tabular}{|l|c|}
\hline \multicolumn{2}{|c|}{ TABLE 4 } \\
Librarians' Benefits of Providing RDM Support, $\mathbf{n}=\mathbf{3 6}$ \\
\hline \multicolumn{1}{|c|}{ Benefits } & $\%$ of librarians \\
\hline Evolving the library's image, role, services & $42 \%$ \\
\hline Supporting RDM is interesting, enjoyable, etcetera & $31 \%$ \\
\hline Learning new things & $28 \%$ \\
\hline Building relationships with researchers & $22 \%$ \\
\hline Being seen as a source of support & $17 \%$ \\
\hline Informing other aspects of the job & $17 \%$ \\
\hline
\end{tabular}

Learning new things, building relationships with faculty and students, being seen as a source of research support, and informing other aspects of their job also were mentioned as benefits (see table 4). Librarian 20 described how interacting with researchers built knowledge and improved service delivery:

"I get exposure to the kind of data they're collecting then the research that they're doing, and then that informs my collection development, and possibly the way I do instruction for the department."

Increasing staff levels was expected to facilitate RDM, but the chances of hiring enough dedicated RDM experts was a long shot. Most libraries had to reskill and reallocate existing staff. Although staff benefited from providing RDM services and were enthusiastic about the possibilities, limited time and multiple responsibilities often constrained RDM activity.

\section{Researchers' Perceptions about the Library}

According to 25 percent of the librarians interviewed, researchers' perceptions about the library constrained RDM programs (see table 1). When thinking about needed RDM support, researchers did not consider the expertise and services librarians could offer. Librarian 06 captured this sentiment well:

"But it is a challenge to get them to move from thinking of us as a big place with books. And going to this much more abstract concept of data management and preservation, and access to their materials. And I would say generally that's a pretty big step for a lot of faculty, even the ones that are more forward thinking."

Some librarians acknowledged researchers' perceptions were partly due to libraries' late entry into RDM. Librarian 34 explained his library's struggle with IR adoption and concern about adding data to it:

"If they're struggling enough to see ... what the point of an IR is, trying to add data to that, it seems like a real leap ... for our faculty to see that. Like I said, we were late in the institutional repository game ... So, we're still I think, trying to get people to realize that 'Oh, yeah, you have this, and what do I use this for?'”

As Librarian 29 explained, researchers on her campus started supporting themselves, because the library did not show any intention toward supporting their RDM needs: 


\begin{abstract}
"So, they just did it on their own because the library - we're a very traditional institution. So, we weren't doing that [helping researchers manage data]. So, we're still working at identifying who's already working on this, and then trying to build a relationship because we're a little late, they're already doing this, and then building up that sort of credibility that we can do this, we're here to do it."
\end{abstract}

Another librarian noted researchers' resistance to adopting new services once they established their own practices. Considering these challenges, librarians expressed concerns about not getting involved. Librarian 30 described it as "a keeping up with the Joneses. If we're not doing it, somebody else is. Then we look like we're falling behind." In fact, a major benefit librarians expected to gain through their RDM work was evolving the library's image, role, and services (see table 4). Librarians were challenged, yet eager to change researchers' perceptions about the library, and saw providing RDM services as one way to do it. As Librarian 07 explained:

“They [researchers] don't really see why they need to back up their data, or discuss how they're going to preserve their data, or manage their data and really organize it in any kind of prolonged way for the future. And I think that once they start to see the benefits and the value of that, that helps put value on the library."

Despite researchers' perceptions about the library's role, librarians wanted to engage, educate, and support researchers' RDM efforts. Librarians saw it as one way to transform perceptions about librarians and the value libraries provide to their campus communities.

\title{
Leadership Support
}

Thirty-one percent of librarians mentioned leadership support within the library and across the broader campus community (see table 1 ). In approximately equal numbers librarians mentioned needing (19\%) and/or having (17\%) leadership support to facilitate their ability to support RDM needs. As Librarian 31 said, having leadership from the top would make it easier to support RDM needs:

"[O]ne of the things that would make it easier is if the leadership were coming from up, higher-you know, if our Research and Sponsored Programs was saying, 'Hey, the library has put this in place, you will use it.' You know, if there was ... leadership from the top rather than what I feel we're trying to do, which is sort of this leadership from the middle, or even bottom."

Those who expressed a need for leadership support wanted to be assured "there is $100 \%$ buy-in from the upper level of the library" (Librarian 03) and explained that their grassroots efforts had reached a point where "it [the Research Data Team] needs higher level people" (Librarian 01). They noted the importance of "having the support of ... the higher ups" (Librarian 07) and having the "leadership ... to make it happen, to say 'We are doing this'" (Librarian 30).

Librarians who had leadership support described the number of ways administrative leaders within and outside the library helped. In one instance, a University President worked with academic affairs, sponsored research, and information technology services to create and recruit a technology expert to complement Librarian 09's RDM work. This same librarian also discussed how library administrators were working to change the library's culture and to help her navigate relationships outside the library: 
“ ... our Dean of Libraries has said, if I'm in my office I'm not doing my job. So, she is really helping to change that culture that, I may be a librarian, but I'm outside the building, a lot. So, there's that kind of permission. Then I also meet with our Associate Dean ... she is very aware of faculty on campus and those political partnerships. She is also there to help me navigate the waters."

Leaders not only advocated for change, but also built relationships across campus to make things happen. Librarians described leaders as champions and advocates who created new jobs, provided rationale for RDM investments and plans, gained support from other areas of the institution, and acknowledged and encouraged researchers' use of libraries' RDM expertise and services.

\section{Communication, Coordination, and Collaboration}

Sixty-seven percent of librarians mentioned some form of communication, coordination, or collaboration with others to facilitate RDM programs. Communication, coordination, and collaboration with colleagues in the library, researchers, other campus units, and institutions off campus were mentioned (see table 5). Librarians tended to discuss existing work they did with others, but there were some who mentioned the need for more joint work, particularly with other units on campus.

Librarians worked with colleagues in the library to define, develop, and deliver RDM services and pool their expertise. Librarian 18 was working with the STEM (Science, Technology, Engineering, and Mathematics) librarian "to figure out what path the library can embark upon to assist faculty." Librarian 21 discussed a strategic development goal that would help her pool her data management expertise with liaison librarians' disciplinary expertise to collaborate on hard problems:

“One of our big goals ... is upskilling our liaison librarians in data management, so they can take point on a lot of the more discipline-specific questions when necessary, and then we could work together and tag team the more difficult problems that come through."

Librarians also mentioned working with researchers to understand their needs and develop and deliver effective RDM programs. For Librarian 10, this work was exemplified by serving on the faculty research committee:

"Being on the faculty research committee is probably one of the most beneficial things for me personally to be aware of who's doing what and then I can let the subject librarian know, 'Did you know that so and so is involved in this project? Please touch base with them to see if they have any data curation needs that we can help them with.'"

\begin{tabular}{|c|c|}
\hline \multicolumn{2}{|c|}{$\begin{array}{c}\text { TABLE } 5 \\
\text { Types of Communication, Coordination, and Collaboration that Facilitate } \\
\text { Librarians' RDM Support, } N=36\end{array}$} \\
\hline Types & $\%$ of librarians \\
\hline With other campus units & $50 \%$ \\
\hline With colleagues in the library & $25 \%$ \\
\hline With researchers & $22 \%$ \\
\hline With other institutions & $8 \%$ \\
\hline
\end{tabular}


Others met with researchers to learn which departments supported versus needed RDM and considered how to capitalize on the existing support. They also developed new services. Helping graduate students figure out "what to do with their research as they were culminating" led Librarian 15 to work with the graduate school to develop a data management workshop for first-year students.

Half of the librarians mentioned working with other campus units to further define, develop, and deliver RDM services and pool expertise. This facilitator was mentioned twice as much as work with library colleagues and researchers. The connections with other campus units had the potential for broader coverage across the data lifecycle. As Librarian 08 said, "It's not a one or the other. It's gonna be a group effort, Research Office, IT, libraries ... Who knows? Maybe, I'm missing somebody." Other campus units, such as sponsored research, academic affairs, IT services, and university archives, had different kinds of expertise and resources to cover more ground. In several cases, librarians mentioned hires or appointments made to cultivate relationships across the various campus groups. For instance, Librarian 27 described the work that the Associate University Librarian for Research did with different departments and areas across campus to form alliances:

"And she has gone out and met with every single unit on campus, every school and college, research, associate deans for research, central research office, IT, and, forming those coalitions."

Working with different campus units also meant librarians needed to outline RDM roles and responsibilities, which was not always easy. Librarian 16 had to negotiate with the sponsored research office when "trying to figure out, what is the set of services a library should offer," but also trying to avoid "doing the compliance work that the Office of Research doesn't want to do." Librarian 35 discussed how the same two units on her campus were collaborating on education initiatives and embedded the library's data management workshop into the sponsored research office's workshop on how to write proposals.

Librarians also wanted other campus units to speak on the library's behalf or, as Librarian 08 explained, advocate partnerships with the library:

"Right now, I think they just have a little web page. Maybe they should sort of back up the libraries by saying, 'Look, you should talk to these people. They can help you with the data management plan. But also once you have that grant, where is this gonna go?' And that's where they need to also, sort of mandate that IT work with the researchers and the library, to make sure that there's something for them ... when they get their data, they'll actually be able to put it somewhere."

By comparison, there was much less mention of communication, coordination, and collaboration with institutions off campus. Only one librarian mentioned contacting other university libraries to see what they are doing and consider possible work together. Although communication, coordination, and collaboration efforts varied, they helped identify and develop campuswide RDM capabilities, given resources and areas of expertise. They also served to lay the foundation for a common, holistic, and shared support infrastructure that could improve service delivery and meet researchers' needs.

\section{Discussion}

This study collected data from 36 academic librarians in the United States via individual and focus group interviews to examine their early experiences supporting RDM. Two- 
thirds had at least some RDM experience. They mentioned providing or planning to provide support to researchers writing data management plans, depositing data, and managing data. Support was offered through consultation, education, and outreach primarily. Given the early stages of RDM programs, this study focused on what librarians perceived as influences on their ability to support researchers' RDM needs.

There were different aspects of technical resources that facilitated and constrained RDM programs. Although digital repositories were perceived as facilitators, the challenges related to data storage and preservation were mentioned twice as much. Findings indicate many librarians did not have the time, money, or full range of expertise needed to support RDM over the lifetime of the data and suggest partnering with other stakeholders to support the range of services needed. Findings also indicate that most librarians acknowledge and rely on existing disciplinary repositories when possible. However, those looking to use an IR for data must consider additional data storage and preservation requirements and stakeholders who can help. In some cases, partnering with the on-campus IT service area may be enough. In other cases, additional off-campus stakeholders may be needed. For instance, Open Context, an archaeological data publisher, relies on the California Digital Library for data preservation. ${ }^{37}$ Staff working in zoological museums at universities around the United States curate and preserve zoological specimens for discovery and access, and collaborate with VertNet, a cross-institutional collaboration among the University of California, Colorado, Kansas, and Tulane. ${ }^{38}$ This partnership enables centralized access to data for easier search and discovery across multiple museums' collections. In these cases, cross-institutional partnerships were formed "to complement and extend each other's capabilities and to add value to the designated community of users." ${ }^{39}$ By inventorying expertise and resources against RDM objectives, librarians can identify and draw upon areas of expertise and capacity on and off campus to address specific aspects of researchers' needs they cannot support.

Like technical resources, different aspects of the human resources facilitated and constrained RDM programs. Having full-time expert staff and education and training opportunities facilitated RDM activity, but in many cases librarians felt they did not have enough staff to scale RDM. Prior research reported reallocating and reskilling existing staff to RDM services as the most common staffing practice. ${ }^{40}$ Similar to this current study, prior research also reported providing support for reskilling through self-study and in-house training. ${ }^{41}$ Findings from this study showed reallocating and reskilling existing staff helped RDM programs, but demands on staff time were a challenge, which suggests the need to consider how to do more with less than optimal staffing levels. Forming different types of collaborations with colleagues in the library to pool expertise is one alternative. These collaborations are important because they simultaneously serve to support researchers' RDM needs and provide needed handson experience while on the job, which librarians reported as a facilitator. By pooling expertise, one librarian is not tasked to address RDM work from multiple skill areas, some of which may be underdeveloped. Instead, a group of librarians can come together to adapt and apply their joint knowledge to RDM tasks. This arrangement has the potential to save time by drawing from librarians' previous experiences to build RDM expertise on the job with others rather than work in isolation.

Findings also suggest librarians consider pooling expertise and resources with libraries at other institutions, which may reduce duplication of effort and demands on staff time. Yet a survey of library directors found that the majority did not have current or planned RDM service collaborations with other institutions in progress. ${ }^{42}$ This lack of collaboration is an area that would benefit from future investigation, since there have been several collaborations among libraries to support RDM activities. The Univer- 
sity of Massachusetts Medical School drew from a prior collaboration with Worcester Polytechnic Institute to lead the development of a STEM-based data management curriculum for undergraduate and graduate students; seven New England institutions collaborated to contribute content. ${ }^{43}$ Collaborative metadata creation and reuse has been occurring within the Ontario Council of University Libraries for shared licensed quantitative data. ${ }^{44}$ More recently, the Data Curation Network project, a collaboration among several institutions, was created to share data curation resources and staff..$^{45}$ Findings suggest another worthwhile alternative is collaborating with other area institutions to create multiple data repository hubs that coordinate RDM activities for underserved disciplines. By implementing cross-institutional repositories at designated universities, staff from area institutions can coordinate support for researchers' RDM needs within disciplines. These repositories would replace the need for individual ones at each institution that support multiple underserved, but disparate, disciplines. This approach has the potential to focus resources, staff expertise, and repository attention on a core set of needs and related data formats, standards, documentation, and so on, within a discipline and across multiple institutions.

Researchers' perceptions of the library constrained RDM programs. Findings indicated perceptions were based on long-held assumptions about librarians and library services and the library's slow response to researchers' RDM needs. Moreover, less than a quarter of the librarians mentioned communicating, coordinating, and collaborating with researchers to facilitate RDM support. Reports on collaboration from prior research vary. In the Tenopir, Birch, and Allard study, librarians report academic departments as common collaborators; but, in the Pinfield et al. study, librarians report a lack of engagement from researchers. ${ }^{46}$ Although liaison librarians have been integral in outreach and education efforts to faculty and students, liaisons are not the only answer. More and different connections between librarians and researchers need to be explored to not only build awareness of researchers' needs and enhance RDM services, but also to build researchers' awareness of librarians' support and to enhance their perception of librarians' abilities to perform RDM services. Findings from this study indicate that engagement with researchers can come in many forms and via different librarian roles. Librarians would do well to consider their various opportunities to engage with faculty and students throughout the research lifecycle from research proposal to publications. For instance, librarians serving on internal grant proposal committees to award institutional funds or partnering with sponsored research offices and graduate schools to lead RDM workshops to present ways to plan, manage, and share data in the early stages of faculty and student research. Such early exposure provides an opportunity for librarians to keep abreast of the challenges researchers face and to proactively plan and partner with researchers to address their RDM needs.

Leadership support is needed to facilitate RDM programs within and across the various service organizations on campus. This finding supports prior research, which shows that relationships between administrators in the library and other service organizations on campus were critical to making progress on RDM programs. ${ }^{47}$ Given that the library often is at the center of RDM efforts, findings suggest library administrators lead a broad-based outreach and education campaign with the goal to meet, greet, teach, negotiate, and learn from other campus units to yield a coalition of support. The goal for effective RDM programs would be to rely on administrative stakeholders across the full set of service organizations to show that the institution supports RDM, advocates for the on-campus RDM program, and believes effective RDM support is the result of the institution's abilities and efforts, not the sole responsibility of the library.

Finally, findings suggest communication, coordination, and collaboration within the institution contributed to RDM programs and aligned with recent discussion about 
RDM programs at large research universities and small liberal arts colleges. ${ }^{48}$ These activities appear to be critical for the design and development of effective RDM. Working together with stakeholders from other service areas at the institution is one way to advance RDM programs. While working with other stakeholders on campus was mentioned frequently, there was less mention of working with stakeholders at other institutions off campus. This finding is consistent with prior research that reports some successful collaborations between different disciplines and institutions. ${ }^{49}$ The literature suggests that librarians begin to think more broadly about whom they can partner with to provide RDM programs, whether it be other libraries or RDM service providers. Given the importance of communication, coordination, and collaboration, librarians should begin working with other stakeholders as ideas for RDM programs are being formulated and the availability and capacity of resources are being evaluated.

\section{Future Research}

Based on the findings from this study and support from several others, future research is warranted to further identify efforts made by academic librarians to work with others on RDM programs, particularly during the design and development phases. Further investigation into the specific aspects involved in planning RDM programs such as librarians' decisions about whether and how to include other on-campus stakeholders in these early phases, the rationale behind the work that ensues, and the RDM program that results, would provide much-needed insight into the design and development stages. A programmatic investigation of the planning discussions associated with services, resources, responsibilities, funding, collaborations, and so on would be beneficial to both those academic librarians considering the provision of RDM services and those already providing RDM services.

The librarians who participated in this study articulated the importance of communicating, coordinating, and collaborating with stakeholders on and off campus. Yet this study and the Tenopir, Birch, and Allard white paper indicate that there is not much interaction across institutions, ${ }^{50}$ and the Pinfield et al. study focuses on stakeholders within an institution only ${ }^{51}$ Future research that considers the partnerships being developed with service providers at other institutions, including how they are initiated and structured and the value that results, would be fruitful. Evaluation of the different RDM programs based on their effectiveness and use could be measured and compared to the level of collaboration involved in designing, developing, and delivering RDM services. The results would be useful in the development of best practices for RDM programs.

\section{Conclusion}

Librarians have successfully established RDM programs on campus to support researchers' needs, but there are still opportunities to more efficiently and effectively support the broad range of activities throughout the data lifecycle. Based on the five influencing factors found in this study, the findings suggest that librarians can pursue these opportunities through broad-based leadership support across the different service organizations on campus and increased communication, coordination, and collaboration with these service organizations and those at other institutions. Finding ways to share support for RDM efforts, particularly technical and human resources, reduces burdens on individual libraries and their institutions. By growing the infrastructure together, no library or institution should create and sustain RDM programs alone.

\section{Acknowledgements}

Thanks goes to Julianna Barrera-Gomez, Alyssa Darden, Erin Hood, and Kendra Par- 
son for their help during data collection and analysis and Vanessa Kitzie and Brittany Brannon for their help during the preparation of this manuscript. Thanks also goes to manuscript reviewers for their comments and suggestions.

\section{APPENDIX A. Questions from Individual Interviews}

1. Tell me about yourself. I would like to hear more about your education, years as a library professional, current job title, and roles and responsibilities.

2. As an academic librarian, what aspects of a researcher's work do you consider to be part of the scholarly record?

3. What data management tasks do you help the researchers perform?

4. Tell me about the researchers, research, and data that you work with. What prompts you to help them? What percentage of your time is spent helping researchers manage their data?

5. What do you see as the challenges of spending time helping researchers at your institution manage their data?

6. What do you see as the advantages of spending time helping researchers at your institution manage their data?

7. What else comes to mind when you think about spending time helping researchers at your institution manage their data?

8. Where is the push for data management services to help researchers coming from at your institution?

9. What individuals or groups support your spending time helping researchers at your institution manage their data?

10. What individuals or groups worry about your spending time helping researchers at your institution manage their data?

11.Sometimes, when we are not sure what to do, we look to see what others are doing. Whom do you look to? What are you seeking?

12. What factors or circumstances make it difficult or prevent you from spending time helping researchers at your institution manage their data?

13. What factors or circumstances make it easy or enable you to spend time helping researchers at your institution manage their data?

14. How competent do you feel when helping researchers manage their data? How confident do you feel that you are providing researchers what they need? What would increase your competence and confidence?

15. What tools, templates, guides, or technologies do you know about and use to help researchers manage their data?

16. What more would you like to say about helping researchers manage their data that I may not have asked?

\section{APPENDIX B. Questions from Focus Group Interviews}

1. We want to start by having everyone introduce themselves. Please tell us your name and use one word to describe what you love about your job.

2. What services do you envision when working with researchers on data management?

3. What department/area in your institution has been championing data management services?

4. What is the motivation behind planning or providing data management services? 
5. What has been your library's involvement to date? What value do you see the library bringing to the effort? What does the library stand to gain in the long term, if anything?

6. What personal benefits do you get from providing data management services/ helping researchers manage data? How do the benefits you get from providing data management services differ from the benefits gained from other kinds of services you provide researchers?

7. What are the challenges of your providing data management services/helping researchers manage data? How do the challenges you mentioned differ from the challenges you encounter when providing other services to researchers?

8. How confident do you feel you can provide the data management support researchers need?

9. How satisfied are you with the amount of time you spend providing data management support?

10. What would make it easier for you to provide data management services/to help researchers manage data/to support researchers' data management?

11. What would you like to add about providing data management services for researchers, helping researchers manage data, and supporting researchers' data management that has not been mentioned or discussed?

\section{Notes}

1. Richard E. Luce, "A New Value Equation Challenge: The Emergence of eResearch and Roles for Research Libraries," in No Brief Candle: Reconceiving Research Libraries for the 21st Century (Washington, D.C.: Council on Library and Information Resources, 2008), available online at www. clir.org/pubs/reports/pub142/luce.html [accessed 28 December 2016].

2. Tracey Gabridge, "The Last Mile: Liaison Roles in Curating Science and Engineering Research Data," in Research Library Issues: A Bimonthly Report from ARL, CNI, and SPARC, no. 265 (New Orleans, La.: Association of Research Libraries, 2009), available online at http://publications. arl.org/rli265/16 [accessed 28 December 2016].

3. Tyler O. Walters and Katherine Skinner, New Roles for New Times: Digital Curation for Preservation (Washington, D.C.: Association of Research Libraries, 2011), available online at www.arl. org/storage/documents/publications/nrnt_digital_curation17mar11.pdf [accessed 28 December 2016].

4. Andrew M. Cox and Stephen Pinfield, "Research Data Management and Libraries: Current Activities and Future Priorities," Journal of Librarianship and Information Science 46, no. 4 (2014): 300, doi:10.1177/0961000613492542.

5. Sheila Corrall, Mary Anne Kennan, and Waseem Afzal, "Bibliometrics and Research Data Management Services: Emerging Trends in Library Support for Research," Library Trends 61, no. 3 (2013): 636-74, doi:10.1353/lib.2013.0005; Carol Tenopir, Ben Birch, and Suzie Allard, Academic Libraries and Research Data Services: Current Practices and Plans for the Future: An ACRL White Paper (Chicago, Ill.: Association of College and Research Libraries, 2012), available online at www. ala.org/acrl/sites/ala.org.acrl/files/content/publications/whitepapers/Tenopir_Birch_Allard.pdf [accessed 28 December 2016]; Karen Antell, Jody Bales Foote, Jaymie Turner, and Brian Shults, "Dealing with Data: Science Librarians' Participation in Data Management at Association of Research Libraries Institutions," College \& Research Libraries 75, no. 4 (2013): 557-74, https://doi. org/10.5860/crl.75.4.557; Rachael Kotarski, Susan Reilly, Eefke Smit, and Karen Walshe, Reports on Best Practices for Citability of Data and on Evolving Roles in Scholarly Communication (Opportunities for Data Exchange, 2012), available online at accessed December 28, 2016, www.stm-assoc. org/2012_07_10_STM_Research_Data_Group_Data_Citation_and_Evolving_Roles_ODE_Report. pdf [accessed 28 December 2016].

6. Stephen Pinfield, Andrew M. Cox, Jen Smith, and Pascal Launois, "Research Data Management and Libraries: Relationships, Activities, Drivers and Influences," PLoS ONE 9, no. 12 (2014): e114734, available online at http://journals.plos.org/plosone/article?id=10.1371/journal. pone.0114734 [accessed 28 December 2016].

7. Ibid.

8. Ibid. 
9. Dictionary.com, s.v. "influence," available online at www.dictionary.com/browse/influence [accessed 28 December 2016]; Merriam-Webster, s.v. "influence," available online at https://www. merriam-webster.com/dictionary/influence [accessed 28 December 2016].

10. Pinfield et al., "Research Data Management and Libraries."

11. Ibid.

12. Ricky Erway, Starting the Conversation: University-Wide Research Data Management Policy (Dublin, Ohio: OCLC Research, 2013), available online at www.oclc.org/content/dam/research/ publications/library/2013/2013-08.pdf [accessed 28 December 2016].

13. Michael Witt, "Institutional Repositories and Research Data Curation in a Distributed Environment," Library Trends 57, no. 2 (2008): 191-201, doi:10.1353/lib.0.0029; Sarah Jones, Alexander Ball, and Çuna Ekmekcioglu, "The Data Audit Framework: A First Step in the Data Management Challenge," International Journal of Digital Curation 3, no. 2 (2008): 112-20, available online at www. ijdc.net/index.php/ijdc/article/view/91 [accessed 28 December 2016].

14. Michael Witt, "Co-Designing, Co-Developing, and Co-Implementing an Institutional Data Repository Service," Journal of Library Administration 52, no. 2 (2012): 172-88; Mark P. Newton, C.C. Miller, and Marianne Stowell Bracke, "Librarian Roles in Institutional Repository Data Set Collecting: Outcomes of a Research Library Task Force," Collection Management 36, no. 1 (2010): 53-67, available online at http://docs.lib.purdue.edu/lib_fsdocs/6/ [accessed 28 December 2016]; Leslie M. Delserone, "At the Watershed: Preparing for Research Data Management and Stewardship at the University of Minnesota Libraries," Library Trends 57, no. 2 (2008): 202-10, doi:10.1353/ lib.0.0032; Jennifer Thomas, "Future-proofing: The Academic Library's Role in E-Research Support," Library Management 32, no. 1/2 (2011): 37-47.

15. Tenopir, Birch, and Allard, Academic Libraries and Research Data Services; Kotarski et al., Reports on Best Practices for Citability of Data.

16. Tenopir, Birch, and Allard, Academic Libraries and Research Data Services.

17. Kotarski et al., Reports on Best Practices for Citability of Data.

18. Corrall, Kennan, and Afzal, "Bibliometrics and Research Data Management Services." 636-74

19. Mary Auckland, Re-skilling for Research: An Investigation into the Role and Skills of Subject and Liaison Librarians Required to Effectively Support the Evolving Information Needs of Researchers (London: Research Libraries UK, 2012), available online at www.rluk.ac.uk/wp-content/uploads/2014/02/ RLUK-Re-skilling.pdf [accessed 28 December 2016].

20. Natasha Simons and Joanna Richardson, "New Roles, New Responsibilities: Examining Training Needs of Repository Staff," Journal of Librarianship and Scholarly Communication 1, no. 2 (2012): eP1051, available online at http://jlsc-pub.org/jlsc/vol1/iss2/7 [accessed 28 December 2016]; Maria Cassella and Maddalena Morando, "Fostering New Roles for Librarians: Skills Set for Repository Managers - Results of a Survey in Italy," Liber Quarterly 21, no. 3/4 (2012): 407-28, available online at https://www.liberquarterly.eu/article/10.18352/lq.8033/ [accessed 28 December 2016].

21. Antell et al., "Dealing with Data," 557-74.

22. Corrall, Kennan, and Afzal, "Bibliometrics and Research Data Management Services," $636-74$

23. Jingfeng Xia and Minglu Wang, "Competencies and Responsibilities of Social Science Data Librarians: An Analysis of Job Descriptions," College E Research Libraries 75, no. 3 (2014): 362-88, available online at https://doi.org/10.5860/crl13-435 [accessed 11 December 2017].

24. Ibid.

25. Cassella and Morando, "Fostering New Roles for Librarians," 407-28.

26. Simons and Richardson, "New Roles, New Responsibilities."

27. Antell et al., "Dealing with Data," 557-74.

28. Kotarski et al., Reports on Best Practices for Citability of Data.

29. Cassella and Morando, "Fostering New Roles for Librarians," 407-28; Simons and Richardson, "New Roles, New Responsibilities"; Corrall, Kennan, and Afzal, "Bibliometrics and Research Data Management Services," 636-674.

30. Corrall, Kennan, and Afzal, "Bibliometrics and Research Data Management Services," 636-74; Simons and Richardson, "New Roles, New Responsibilities"; Tenopir, Birch, and Allard, Academic Libraries and Research Data Services.

31. Tenopir, Birch, and Allard, Academic Libraries and Research Data Services.

32. Kotarski et al., Reports on Best Practices for Citability of Data.

33. Corrall, Kennan, and Afzal, "Bibliometrics and Research Data Management Services," 636-74.

34. Pinfield et al., "Research Data Management and Libraries."

35. Lynn Silipigni Connaway and Marie L. Radford, Research Methods for Library and Information Science, 6th ed. (Littleton, Colo.: Libraries Unlimited, 2016): 249-50. 


\section{Librarians' Perspectives on the Factors Influencing RDM Programs 119}

36. Ibid.

37. Eric Kansa and Sarah Whitcher Kansa, "Toward A Do-It-Yourself Cyberinfrastructure: Open Data, Incentives, and Reducing Costs and Complexities of Data Sharing," in Archaeology 2.0: New Approaches to Communication \& Collaboration, Cotsen Digital Archaeology Series (Los Angeles, Calif.: Cotsen Institute of Archaeology Press, 2011) 57-91, available online at https:// escholarship.org/uc/item/1r6137tb [accessed 28 December 2016].

38. "Home," VertNet, last modified April 27, 2016, available online at www.vertnet.org/ [accessed 28 December 2016].

39. Ixchel M. Faniel and Elizabeth Yakel, "Practices Do Not Make Perfect: Disciplinary Data Sharing and Reuse Practices and Their Implications for Repository Data Curation," in Curating Research Data Volume 1: Practical Strategies for Your Digital Repository, ed. Lisa R. Johnston (Chicago, Ill.: Association of College and Research Libraries, 2017), 103-125.

40. Pinfield et al., "Research Data Management and Libraries"; Tenopir, Birch, and Allard, Academic Libraries and Research Data Services.

41. Corrall, Kennan, and Afzal, "Bibliometrics and Research Data Management Services," 636-74; Simons and Richardson, "New Roles, New Responsibilities"; Tenopir, Birch, and Allard, Academic Libraries and Research Data Services.

42. Tenopir, Birch, and Allard, Academic Libraries and Research Data Services.

43. Donna Kafel, Andrew Creamer, and Elaine Martin, "Building the New England Collaborative Data Management Curriculum," Journal of eScience Librarianship 3, no. 1 (2014), available online at http://escholarship.umassmed.edu/jeslib/vol3/iss1/7 [accessed 28 December 2016].

44. Jane Fry and Amber Leahey, "Metadata for Social Science Data: Collaborative Best Practices," in Databrarianship: The Academic Data Librarian in Theory and Practice, eds. Lynda Kellam and Kristi Thompson (Chicago, Ill.: Association of College and Research Libraries Press, 2016), 269-82.

45. "Home," Data Curation Network, available online at https://sites.google.com/site/datacurationnetwork/home [accessed 28 December 2016].

46. Pinfield et al., "Research Data Management and Libraries"; Tenopir, Birch, and Allard, Academic Libraries and Research Data Services.

47. Pinfield et al., "Research Data Management and Libraries."-

48. Alicia Hofelich Mohr, Lisa R. Johnston, and Thomas A. Lindsay, "The Data Management Village: Collaboration among Research Support Providers in the Large Academic Environment," in Databrarianship: The Academic Data Librarian in Theory and Practice, eds. Lynda Kellam and Kristi Thompson (Chicago, Ill.: Association of Research Libraries, 2016), 51-66; Ryan Clement, "The Data Librarian in the Liberal Arts College," in Databrarianship: The Academic Data Librarian in Theory and Practice, eds. Lynda Kellam and Kristi Thompson (Chicago, Ill.: Association of College and Research Libraries, 2016), 67-79.

49. Tenopir, Birch, and Allard, Academic Libraries and Research Data Services.

50. Ibid.

51. Pinfield et al., "Research Data Management and Libraries.." 